\title{
KETRAMPILAN RAJUT MENGANTAR SISWA SMK EL HAYAT SIAP BERWIRAUSAHA
}

\author{
Budi Siswanto $^{1)}$, Dewi Astuti Mochtar ${ }^{2)}$, Eko Yuni Prihantono ${ }^{3)}$ \\ Fak. Ilmu Sosial \& Ilmu Politik Universitas Merdeka Malang ${ }^{1)}$ \\ Fak. Hukum Universitas Merdeka Malang ${ }^{2}$ \\ Program D3 Keuangan Dan Perbankan Universitas Merdeka Malang ${ }^{3)}$
}

\begin{abstract}
Abstrak
Tujuan didirikannya SMK adalah menghasilkan tenaga terdidik yang siap kerja, dengan berbagai ketrampilan yang diberikan untuk mengasah hard skill maupun softskill mereka harapannya adalah ketika lulus siswa siap kerja. Namun seiring dengan perkembangan jaman, berjalannya waktu, persaingan yang ketat menyebabkan ketersediaan lowongan kerja bagi siswa yang lulusan SMK menjadi semakin sempit, untuk itulah maka siswa SMK sekarang tidak lagi diarahkan untuk bekerja kepada orang lain namun harus bisa membuka lowongan atau menciptakan kerja sendiri. Berdasar kenyataan itu maka berbagai kegiatan pelatihan untuk menunjang kemandirin mereka terus diberikan.

Ketrampilan pembuatan berbagai asesoris dari bahan rajut menjadi pilihan untuk diberikan kepada siswa SMK, karena asesoris rajut saat ini mengalami peningkatan permintaan, baik sebagai asesoris kecantikan, sebagai hadiah ulang tahun maupun untuk cinderamata pernikahan. Hasil ketrampilan pembuatan cinderamata berupa aneka mainan untuk gantungan kunci, jepit rambut, bros. Diharapkan dengan ketrampilan pembuatan asesoris ini siswa SMK El Hayat utamanya bisa menghasilkan produk yang bisa dijual saat ada pameran sekolah atau pada saat ikut pameran di luar sekolah.

Merajut adalah metode membuat kain, pakaian atau perlengkapan busana, aneka suvenir (gantungan kunci) dari benang rajut, Rajut dapat diartikan jaring/jala, jala atau bahan pakaian yang disirat manual (menggunakan tangan) maupun menggunakan mesin rajut. Sedangkan Rajutan dapat diartikan bahan pakaian yang dibuat oleh tangan maupun mesin rajut atau dapat pula diartikan hasil merajut. Hasil rajutan dapat berupa pakaian, tas, kaos kaki, topi, vest dan baju bayi, aneka suvenir (gantungan kunci) Ada beberapa jenis benang yang bisa dimanfaatkan untuk membuat kain rajut seperti benang katun, polyester serta sutra yang dipintal menjadi benang.
\end{abstract}

Kata Kunci : SMK, Ketrampilan Rajut, Kemandirian

\section{PENDAHULUAN}

Salah satu strategi pemerintah menekan angka pengangguran pada usia sekolah adalah dengan memperbanyak pendirian SMK. Sekolah kejuruan dianggap sebagai langkah strategis mengantisipasi tingginya angka pengangguran pada anak usia sekolah, mengingat bahwa tidak semua anak lulusan sekolah menengah dapat melanjutkan pendidikannya pada jenjang pendidikan tinggi. Peserta didik pada sekolah kejuruan dibekali sejumlah keterampilan atau keahlian yang dibutuhkan oleh dunia usaha khususnya industri, sehingga diharapkan bahwa setelah tamat sekolah bisa langsung bekerja.

Dalam Undang-Undang Sistem Pendidikan Nasional Nomor 20 Tahun 2003 pasal 15, dikatakan bahwa pendidikan menengah kejuruan bertujuan untuk menyiapkan peserta didik terutama untuk bekerja dalam bidang tertentu. Tujuan tersebut kemudian dijabarkan kembali oleh direktorat pendidikan menengah kejuruan (dikmenjur) menjadi dua tujuan, yaitu tujuan umum dan tujuan khusus. Tujuan umum sekolah menengah kejuruan adalah; 1) menyiapkan peserta didik agar dapat menjalani kehidupan secara layak, 2) meningkatkan keimanan dan ketakwaan peserta didik, 3) menyiapkan peserta didik agar menjadi warga negara yang mandiri dan bertanggung jawab, 4) menyiapkan peserta didik agar memahami dan menghargai keanekaragaman budaya bangsa Indonesia, dan 5) menyiapkan peserta didik agar menerapkan dan memelihara hidup sehat, memiliki wawasan lingkungan, pengetahuan dan seni. Sedangkan tujuan khususnya adalah; 1) menyiapkan peserta didik agar dapat bekerja, baik secara mandiri atau mengisi lapangan pekerjaan yang ada di dunia usaha dan industri sebagai tenaga kerja tingkat menengah, sesuai dengan bidang dan program keahlian yang diminati, 2) membekali peserta didik agar mampu memilih 
karir, ulet dan gigih dalam berkompetisi, serta mampu mengembangkan sikap profesional dalam bidang keahlian yang diminati, dan 3) membekali peserta didik dengan Ilmu Pengetahuan dan Teknologi (IPTEK) agar mampu mengembangkan diri sendiri melalui jenjang pendidikan yang lebih tinggi. Untuk merealisasikan tujuan-tujuan tersebut, pemerintah kemudian mengembangkan tiga model kurikulum yang diberlakukan pada sekolah kejuruan, yaitu kurikulum normatif, kurikulum adaptif, dan kurikulum produktif.

Kurikulum normatif adalah kumpulan mata pelajaran yang akan diajarkan kepada peserta didik dengan lebih menekankan pada mengetahuan kognitif. Jenis kurikulum ini selain ada atau ditemukan pada sekolah kejuruan juga ditemukan pada sekolah menengah. Misalnya, mata pelajaran Bahasa Indonesia, Bahasa Inggris, Matematika, PKn, dan lain-lain. Kurikulum adaptif, adalah kumpulan mata pelajaran yang diajarkan pada semua sekolah kejuruan (SMEA, STM, SMKK, SMK Pariwisata, dll) dengan menekankan pada keterampilan atau skill; sedangkan kurikulum produktif adalah kumpulan mata pelajaran yang menjadi ciri khas dari setiap sekolah kejuruan. Aspek yang paling ditekankan pada kurikulum ini adalah keahlian yang akan menjadi keunggulan lulusan. Dengan demikian, akan berbeda jenis kurikulum produktif antara satu SMK dengan SMK lainnya, tergantung pada ciri khasnya. Memperhatikan desain kurikulum yang diberlakukan pada sekolah kejuruan, nampaknya pemerintah telah membuat grand design bahwa siswa lulusan sekolah kejuruan tidak akan ada yang menjadi pengangguran. Karena asumsinya adalah kurikulum normatif menjadi bekal siswa jika ingin melanjutkan pendidikan pada jenjang yang lebih tinggi, kurikulum adaptif menjadi bekal siswa memasuki dunia usaha atau industri, sedangkan kurikulum produktif menjadi bekal siswa untuk menciptakan lapangan kerja secara mandiri. Sebagai kegiatan penunjang kurikulum produktif SMK El Hayat telah melakukan berbagai bentuk kerjasama dengan Perguruan Tinggi yang peduli terhadap pendidikan salah satunya adalah Universitas Merdeka Malang. Salah satu kegiatan adalah pelatihan pembuatan berbagai kerajinan rajut.

\section{METODE KEGIATAN}

Masa sekarang dengan semakin berkembangnya IT menyebabkan anak terampil dalam menghasilkan karya produktif semakin langka, melihat kenyataan ini maka kita harus terus berusaha menggugah semangat anak anak kita untuk bisa berkarya. Dengan melihat potensi wilayah sekitar SMK El Hayat terdapat sebuah UKM yang bergerak di bidang produk rajut, maka setelah dilakukan koordinasi dengan pihak SMK El Hayat ditetapkan akan dilakukan pelatihan Rajut bagi siswa SMK tersebut. Pelatihan rajut ini dimaksudkan untuk menciptakan kemandirian siswa SMK El Hayat, kegiatan difokuskan pada kegiatan merajut berbagai macam cinderamata, dengan harapan siswa setelah lulus bisa membuka peluang usaha sendiri. Metode pelatihan dilakukan dengan metode tutorial dan langsung praktek dipandu 1 narasumber dengan 2 orang asisten, 30 siswa yang mengikuti pelatihan dengan mudah bisa segera menerima pembelajaran yang diberikan. Diharapkan siswa yang mengikuti pelatihan bisa menularkan ketrampilannya kepada teman temannya, sehingga ketrampilan ini tidak berhenti hanya sebatas saat pelatihan saja.

Merajut adalah metode membuat kain, pakaian atau perlengkapan busana, aneka suvenir (gantungan kunci) dari benang rajut, Rajut dapat diartikan jaring/jala, jala atau bahan pakaian yang disirat manual (menggunakan tangan) maupun menggunakan mesin rajut. Sedangkan Rajutan dapat diartikan bahan pakaian yang dibuat oleh tangan maupun mesin rajut atau dapat pula diartikan hasil merajut. Hasil rajutan dapat berupa pakaian, tas, kaos kaki, topi, vest dan baju bayi, aneka suvenir (gantungan kunci) Ada beberapa jenis benang yang bisa dimanfaatkan untuk membuat kain rajut seperti benang katun, polyester serta sutra yang dipintal menjadi benang.

Selain ketrampilan rajut, juga diberikan pelatihan kewirausahaan yakni bagaimana berbisnis yang legal dan bagaimana memasarkan produk. Adanya pelthan kewirausahaan diharapkan membuka wawasan siswa untuk semangat membuka peluang usaha sndiri tanpa harus bergantung pada pihak lain, dengan melakukan bisnis sederhana namun tidak melanggar undang undang, dengan menggunakan metode pemasaran langsung kepada teman, konsinysi dengan menitipkan produk hasilnya kepada pihak lain, atau mengikuti pameran produk yang digelar disekolah atau di instansi lain. Bahkan jika memungkinkan pemasaran dilakukan secara online.

\section{HASIL DAN PEMBAHASAN}

\subsection{Kegiatan pembuatan produk rajut}

Dari kegiatan pembuatan produk rajut siswa bisa menghasilkan gantungan kunci dengan berbagai 
bentuk antara lain: jamur, strawbery, jagung,donat, burung hantu, octopus. Selain itu juga diajarkan membuat produk kaos kaki dan tas rajut. Bahan yang dipergunakan dalam pembuatan produk rajut adalah benang polyester, dakron, alat rajut.

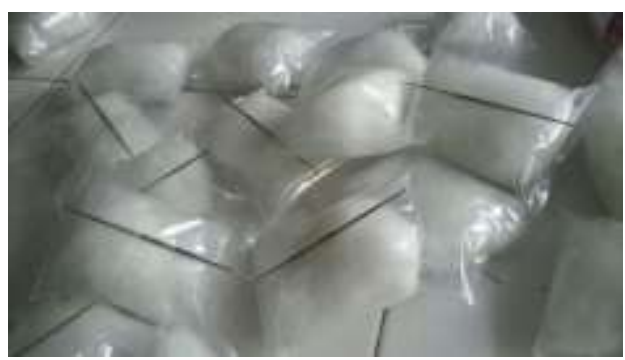

Gb 1. Dakron bahan isian gantungan kunci

Dakron merupakan bahan baku yang dipakai untuk isian gantungan kunci sehingga hasil rajutan bisa dibentuk menyerupai benda aslinya.

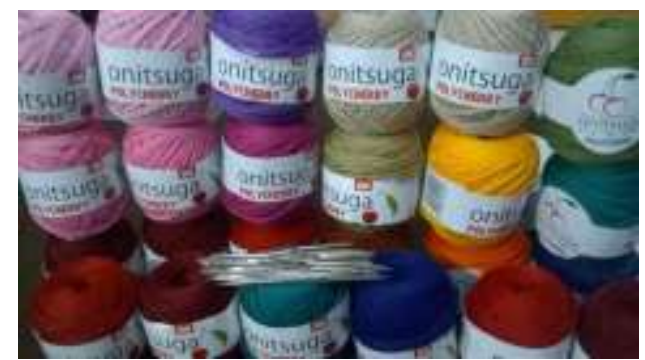

Gb 2. Benang polyester bahan pembuatan rajut

Benang rajut yang digunakan adalah benang poly dengan berbagai warna menyesuaikan dengan kebutuhan produk apa yang akan dihasilkan Aktivitas pelatihan dimulai dengan perkenalan tim dengan peserta pelatihan (siswa SMK Elhayat), setelah itu dilanjutkan dengan pelatihan kewirausahaan dan ketrampilan pembuatan produk rajut. Dalam kesempatan pelatihan kewirausahaan siswa merasa mendapatkan support dan wawasan untuk memulai melakukan kegiatan produktif tidak hanya sekedar belajar di kelas saja

Siswa SMK El Hayat selama ini sering mendengar kegiatan pembuatan produk rajutan, namun mereka belum pernah mempraktekkan sendiri bagaiman proses merajut. Dalam benak mereka selama ini kegiatan merajut sangat susah dan hanya digeluti oleh orang tua, namun setelah mereka melihat dan mencoba sendiri ternyata tidak susah membuat rajutan, dan mitos rajutan hanya dilakukan orang tua hilang.
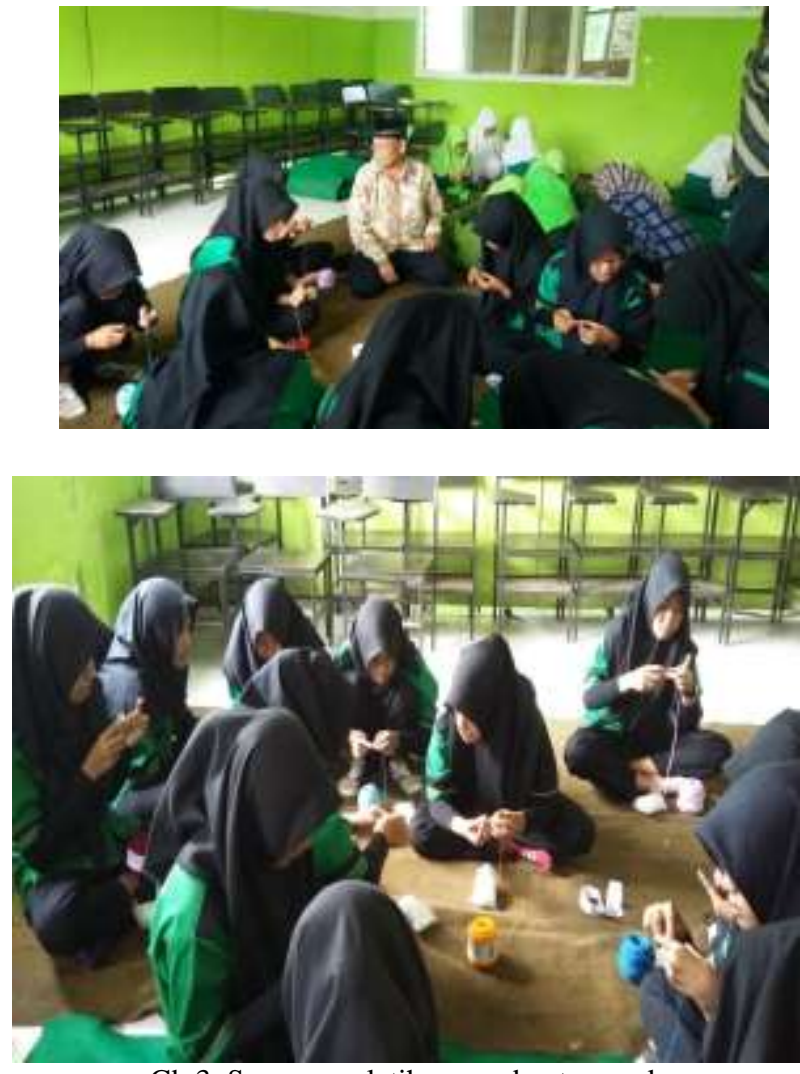

Gb 3. Suasana pelatihan pembuatan aneka gantungan kunci

Dalam proses pelatihan dasar rajut siswa menikmati sekali proses kegiatan pelatihan, dan ketika memasuki proses membentuk beberapa siswa merasa kesulitan, namun ketika diberikan arahan oleh tim siswa bisa merajut dengan lancar. Selama pelatihan berlangsung beberapa produk gantungan kunci bisa dihasilkan oleh siswa SMK walaupun hasil belum maksimal. Ada beberapa siswa yang mampu menghasilkan gantungan kunci yang sempurna, bahkan mampu membuat tas dan kaos kaki dengan baik.

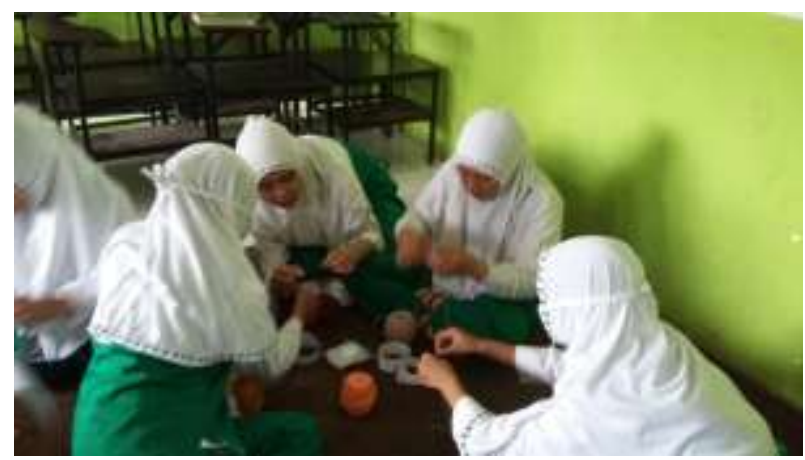

$\mathrm{Gb}$ 4. Suasana pelatihan pembuatan tas rajut 


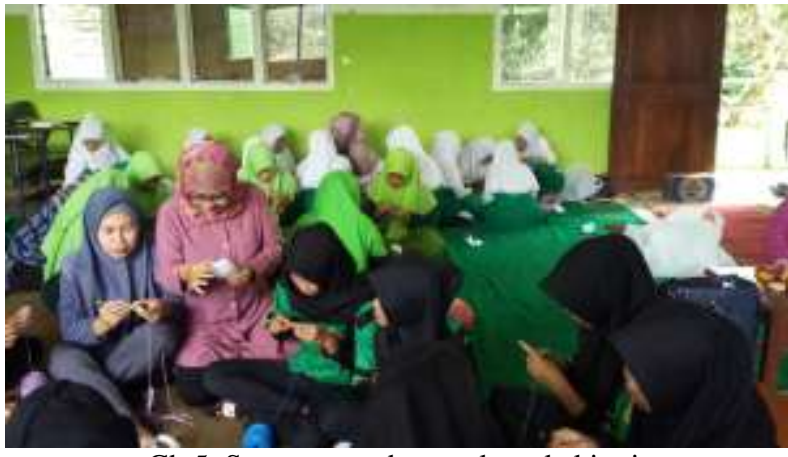

Gb 5. Suasana pembuatan kaos kaki rajut

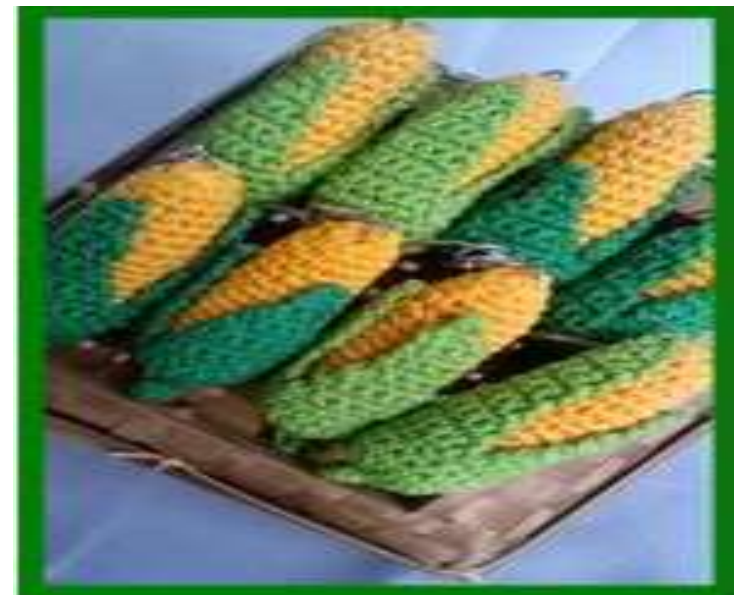

Gb 6 gantungan kunci jagung

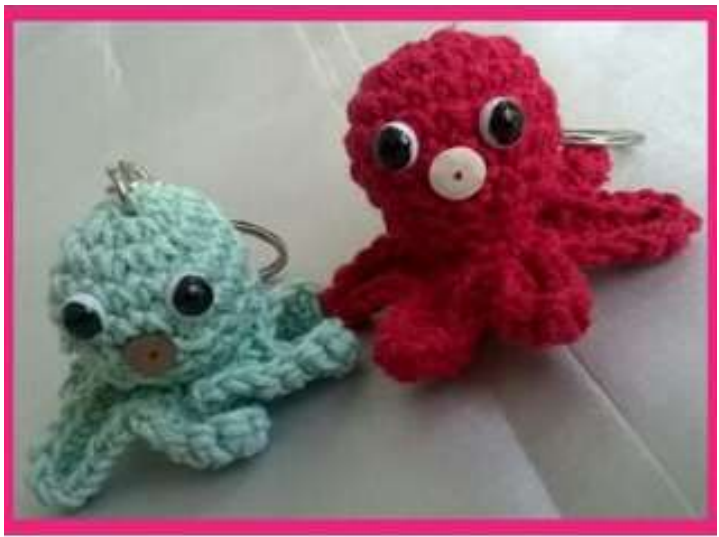

Gb 7 gantungan kunci oktopus
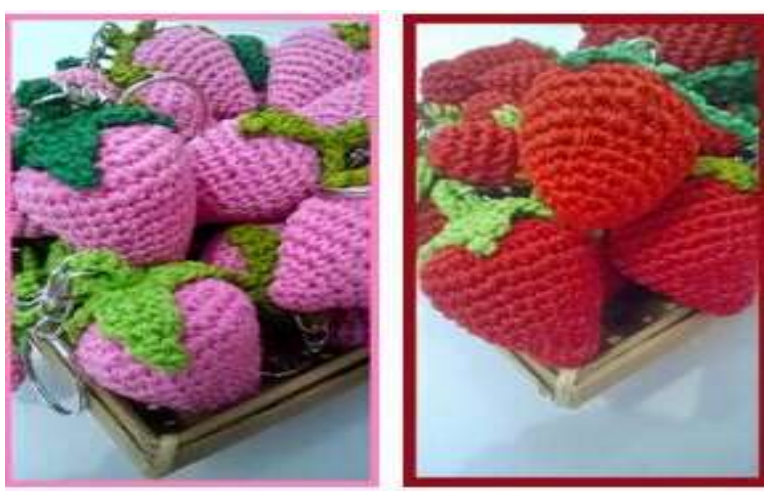

Gb 8. gantungan kunci strowberry

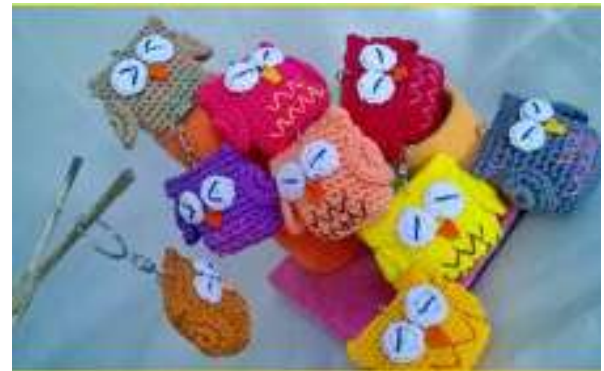

Gb 9. gantungan kunci burung hantu

Aneka gantungan kunci ini jika dijual dipasaran harga berkisar antara Rp 6.500,- s/d Rp 10.000,perbiji. Sementara untuk tas rajut berkisar antara Rp 275.000,- s/d Rp 350.000,-

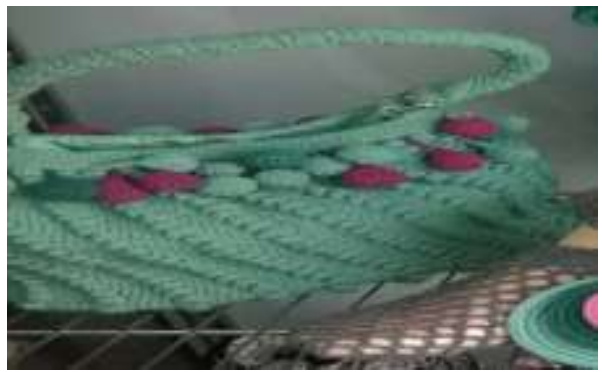

Gb 11 hasil ketrampilan tas rajut

\subsection{Kegiatan pelatihan kewirausahaan}

Kegiatan pelatihan di SMK El Hayat, telah mampu membangkitkan semangat siswa untuk memulai usaha, yang selama ini hanya mereka angankan.

Siswa SMK beranggapan bahwa kalau masih sekolah maka mereka tidak bisa bekerja/berbisnis. Tentunya hal ini perlu diluruskan, karena dalam kondisi apapun sebenarnya kita bisa melakukan aktivitas bisnis, walaupun hanya sebagai perantara. Dalam 24 jam sehari dikurangi jam sekolah siswa masih memiliki waktu luang yang lebih banyak dibanding waktu belajar, sehingga dengan banyaknya waktu luang ini siswa bisa memanfaatkan dengan membuat berbagai ketrampilan antara lain dengan membuat rajutan.

Sekolah SMK El Hayat berada dalam satu kelurahan dengan usaha Rajut Gawean VissTy, dimana pemilik usaha rajut sangat welcome unuk memberikan ilmu rajutnya kepada masyarakat sekitar tak terkecuali bagi siswa SMK El Hayat, demikian juga dengan proses pemasaran. Usaha Rajut Gawean VissTy bersedia menerima hasil rajutan jika memenuhi standart yang ditetapkan, sehingga ini merupakan peluang yang tidak boleh dilepaskan oleh siswa SMK El Hayat, untuk memulai kegiatan usaha dengan bermitra bersama UKM Rajut Gawean VissTy 


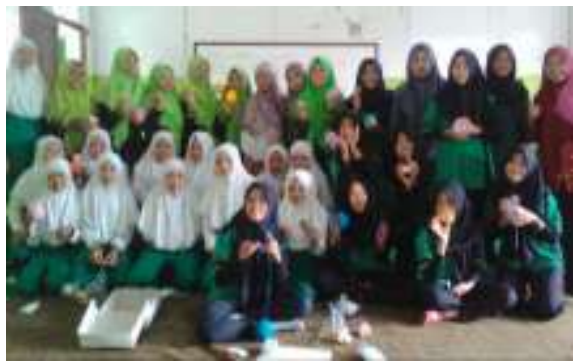

$\mathrm{Gb}$ 12. peserta pelatihan kewirausahaan

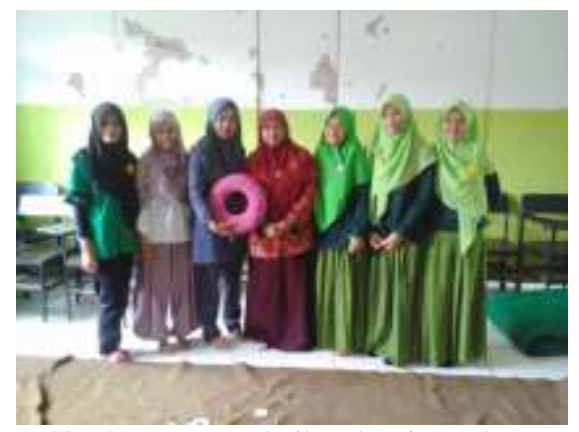

Gb 13 Peserta pelatihan kewirausahaan dengan pemilik usaha Gawean VissTy

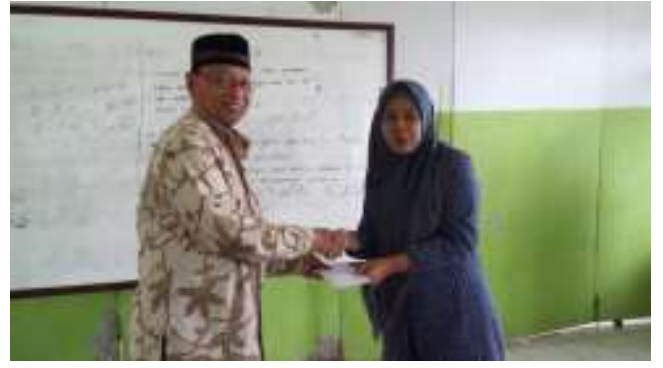

$\mathrm{Gb}$ 14. pemberian bantuan biaya pengadaan bahan ketrampilan rajut

\section{KESIMPULAN}

\subsection{Kesimpulan}

Perkembangan jaman menantang setiap manusia untuk melakukan kegiatan produktf, inovatif dan kreatif. Dengan kemampuan ini seseorang akan bisa memenangkan persaingan. Sebagai lembaga pendidikan vokasi yang berorientasi menyiapkan tenaga siap kerja dan siap bersaing tentunya ketrampilan baik soft maupun hard siswa binaan harus senantiasa ditingkatkan. SMK El Hayat sebagai salah satu isntitusi pendidikan vokasi memiliki tujuan sebagai beriku

1. Menyiapkan siswa untuk memasuki lapangan kerja serta mengembangkan sikap profesionalisme

2. Menyiapkan siswa agar mampu berkarier, mampu berkompetisi dan mampu mengembangkan diri
3. Menyiapkan tamatan agar menjadi warga produktif, inovatif, dan kreatif

Tentunya sesuai dengan tujuan diatas SMK harus lebih banyak praktek dalam orientasi kurikulumnya, sebagai salah satu penunjang kurikulum SMK diadakan berbagai pelatihan baik internal lembaga maupun hasil kerjsama dengan pihak eksternal salah satunya adalah pelatihan pembuatan produk rajut dan kewirausahaan.

Kegiatan pelatihan kewirausahaan dan latihan pembuatan produk rajut telah membekali siswa untuk mampu mengembangkan sikap prosefionalisme dengan membuka wawasan mereka tentang tanggungjawab sebagai seorang wirausaha, mampu dan mau mengembangkan diri, mampu menghasilkan produk serta berinovasi dan kreatif.

Sikap siswa ini terlihat ketika mereka diberi batasan waktu untuk mengerjakan sebuah produk mereka mampu menyelesaikan produk tepat waktu. Selain iu produk yang mereka hasilkan pun tidak sekedar apa yang dicontohkan tetapi banyak variasi hiasan dan bentuk yang mereka buat, hal ini memperlihatkan bahwa siswa kreatif dan inovatif.

Hasil pengamatan dan perbincangan tim dengan siswa dan pemilik usaha Rajut Gawean Vissty, siswa siap untuk membuat gantungan kunci dengan binaan pemilik usaha rajut, sementara pihak pemilik usaha rajut juga bersedia menerima hasil karya siswa selama memenuhi standart yang ditetapkan oleh usaha rajut tersebut. Dari sini keberlanjtan kegiatan pengabdian terjaga dan akan memberikan kemanfaatan bagi kedua belah pihak, baik bagi SMK El Hayat maupun usaha Rajut Gawean VissTy.

\subsection{Saran}

a. Bagi siswa SMK El Hayat harus senantiasa berusaha mengembangkan diri untuk melatih ketrampilannya utamanya membuat produk rajut

b. UKM Gawean Vissty diharapkan memberikan kesempatan siswa SMK El Hayat untuk mengasah ketrampilannya dengan belajar digaleri Vissty

\section{DAFTAR PUSTAKA}

Rudihont Wakatobi, 27 okt 2016 Urgensi sekolah menengah kejuruan http://larudiwakatobi.blogspot. co.id/2016/10/urgensi-pendirian-sekolah-kejuruan 27.html.

Permana, 2015, 7 ide kreatif kerajinana tangan dari benangwool,http://kerajinantanganbagus.blogspot.co.i d/2015/06/kerajinan-tangan-dari-benang.html

Sugi, 2014 http://www.bundasugi.com/2014/09/ panduanmerajut-untuk-pemula.htm 